\title{
EFFECT OF POLYPROPYLENE FIBERS LENGTH AND CONTENT ON CRACKS DEVELOPMENT IN CLAY LINING
}

\author{
Ahmed F. Khalifa ${ }^{1}$, Mohamed Saad Eldin mohamed², Abdullah M. Galaa ${ }^{1}$ \\ ${ }^{1}$ Housing and Building National Research Center \\ (HBRC) 87 El-Tahrir Street, Dokki, Giza, Egypt \\ ${ }^{2}$ Faculty of Engineering Al-Azhar University, Nasr City, Cairo, Egypt \\ fathy.ahmed131119@gmail.com \\ Received :12 Sept. 2021 Accepted:19 Oct. 2021
}

\begin{abstract}
Clay represents an essential component used for lining and containment purposes. Clay performance as a liner is seriously affected by environmental changes and there is a need to limit such volumetric changes. Reinforcing clay with fibers is one of the techniques to limit desiccation volumetric changes. This study presents experimental program to study the effect of the inclusion of randomly distributed polypropylene fibers (PPF) with different lengths on the resistance of clay to desiccation cracking under multiple wetting-drying cycles. Specimens of unreinforced kaolinite clay as well as reinforced clay with PPF with lengths of $6 \mathrm{~mm}, 12 \mathrm{~mm}$ and $18 \mathrm{~mm}$ and fiber contents of $0.5 \%, 0.7 \%, 1.0 \%$, and $1.50 \%$ PPF (by weight) are utilized in the study. Desiccation cracking is quantified by calculating Cracking Intensity Factor (CIF) values. The results show that the inclusion of fibers enhances the resistance to cracking up to certain fiber content after which such resistance decreases. The results also show that resistance of the reinforced clay to cracking. On the other hand, multiple wetting and drying reduces the effectiveness of fibers inclusion to resist desiccation cracking under multiple wetting and drying. However, longer fibers showed better resistance to cracking upon wetting and drying.
\end{abstract}

KEYWORDS: Fiber-reinforced clay, Desiccation cracking, Wetting and drying cycles, Lining. 


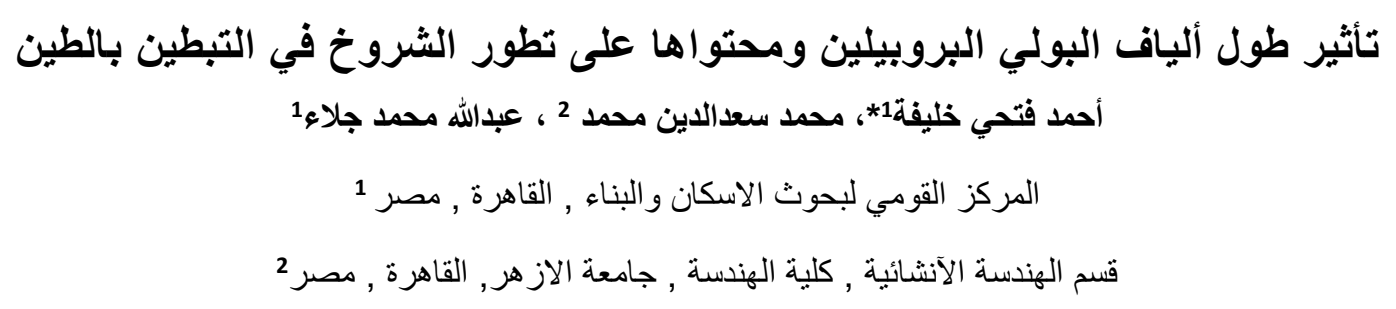

البريد الاليكتروني للباحث الرئيسى: fathy.ahmed131119@gmail.com

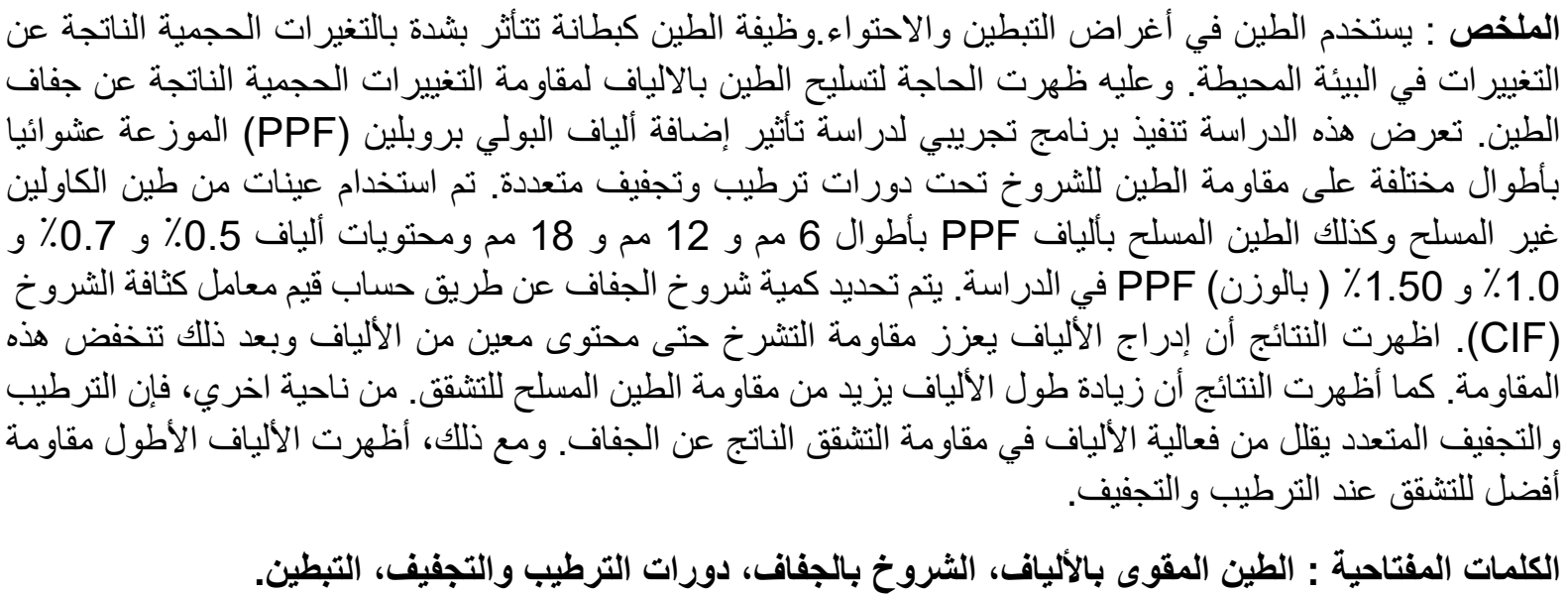

\section{INTRODUCTION}

Over the past two decades, attention has been increasing to the use of natural, synthetic and engineered fibers as tension resistance elements to increase the durability of clay liners and its resistance to cracking as well as to increase the bearing capacity of the clay. Reinforced clays are utilized in different applications such as earth embankments, dams, lining and containment systems for landfills and water channels. In such applications, reinforced clays are subject to ceaseless wetting and drying cycles due to environmental conditions. Reinforcing clays with randomly distributed fibers is a promising methodology as more competent materials were presented with advancements in polymers manufacturing technologies over the past decades.

Various publications addressed the effects of fiber inclusion on the physical, mechanical, volume change, and hydraulic properties of the clay. Fibers have been found to increase the compressive and tensile strength of clay as well as its resistance to desiccation cracking.

Plé and Lê (2011), Sabat (2012), Malekzadeh and Bilsel (2012) and Maheshwari et al. (2013) found that maximum dry density is reduced by including fibers to the tested soils due to the lower unit weight of the fibers compared to that of the soil. Moreover, the optimum moisture content was found to increase in response to the increase in fibers content.

Malekzadeh and Bilsel (2012), Maheshwari et al. (2013), and Qiang et al. (2014) tested clays strengthened with fibers contents extending from $0 \%$ to $>0.5 \%$. They found that the inclusion of fibers improves the unconfined compressive strength (UCS) up to $0.3 \%$ fibers content after which, UCS declines. Tang et al. (2006) and Plé and Lê (2011) showed an increase in UCS with the increase in fibers content and no decrease in UCS with increase of fibers content. 


\section{EFFECT OF POLYPROPYLENE FIBERS LENGTH AND CONTENT ON CRACKS \\ DEVELOPMENT IN CLAY LINING}

Maher and Ho (1994) and Chegenizadeh and Nikraz (2011) tested fiber reinforced clays with fibers content 5\% and did not report any decrease in UCS with the increase in fiber content. Direct shear testing performed Tang et al. (2006) reported an increase in the shear strength parameters with fibers content for clays reinforced with up to $0.25 \%$ fibers. Qiang et al. (2014) showed an increase in shear strength parameters up to a fibers content of $0.3 \%$ then to decrease with further addition of fibers.

To explore the impact of fibers consideration on the tensile strength on strengthened clay, Malekzadeh and Bilsel (2012) conducted split-tensile tests. they found that, the tensile strength increaser with the increase of fibers and no reduction was reported as compared to UCS, which agrees with conclusions of Maher and Ho (1994) and Ziegler et al. (1998).

Resistance to desiccation cracking was examined by numerous researchers utilizing different methodologies. Qiang et al., (2014) and Chaduvula et al., (2017) reported that, the inclusion of fibers enhances the resistance to cracking up to $0.75 \%$ fibers content after which such resistance decreases. However, other results reported by Rifai et al. (2009) and Chegenizeadeh and Nikraz (2011) did not show such reduction in resistance to cracking with increase of fiber content.

The effect of multiple wetting and drying cycles on the development of desiccation cracking was investigated by several researchers. There is an agreement that the effectiveness of the fiber inclusion in reduction desiccation cracking is significantly reduced after applying wetting and drying cycles (Ziegler et al, (1998); Yesiller et al., (2000); Qiang et al., (2014); and Estabragh et al., (2014).

A previous study conducted by (Galaa et al., 2018) investigated the effect of using $6 \mathrm{~mm}$ long PPF as a reinforcement to Kaolinite clay on the compressive strength as well as resistance to desiccation cracking. The results showed that inclusion of $0.5 \% 6 \mathrm{~mm}$ long PPF with kaolinite clay provides the best resistance to cracking. On the other hand $1 \%$ PPF was found to be of lower resistance to cracking than unreinforced clay after a number of drying and wetting cycles.

There is a general consensus in the published studies on the negative effect of multiple wetting and drying cycles on effectiveness of the fiber inclusion to reduce resisting desiccation cracking (Ziegler et al., (1998) ; Yesiller et al., (2000); Qiang et al., (2014) ; Estabragh et al., (2014); and Galaa et al., (2018) . Yesiller et al. (2000) provided a detailed explanation for reduced resistance to cracking upon wetting and drying where such deterioration is attributed to softening is soil strength upon each wetting cycle. Subsequent drying to each of the wetting cycles induces suction; which exceeds the resistance of the weakened soils causing cracking at locations of decreased soil strength. The soil fabric experiences irreversible changes during the wetting of compacted soil after the first cycle. Wetting may induce healing of some or all of the developed cracks. However, crack locations remain weaker and reopens with each drying cycle. In addition, healed crack locations represent a favorable zone for the inception of further cracks. Therefore, the energy (suction) required to develop new cracks is less than that required in the first cycle.

This paper focused on investigating the impact of using polypropylene fibers (PPF) with different lengths on desiccation cracking of kaolinite clay. Moreover, the impact of using PPF content covering the range from $0.5 \%$ to $1.5 \%$ is investigated in this study. The impact of wetting and drying cycles on the resistance of fiber-reinforced clay to desiccation cracking has also been studied. 


\section{EFFECT OF POLYPROPYLENE FIBERS LENGTH AND CONTENT ON CRACKS DEVELOPMENT IN CLAY LINING}

\section{MATERIALS AND TESTING METHODS}

\subsection{Materials properties}

The kaolinite clay soil used in this study is obtained from Sinai Quarrying Company. Index properties and grain size distribution (GSD) were determined in the laboratory. The tested clay can be classified as low plasticity clay (CL) according to the Unified Soil Classification System (USCS). Clay properties are summarized in Table 1 and GSD is shown in Figure 1. The Standard Proctor Test was carried out on the clay to determine the optimum moisture content (O.MC.) and the maximum dry density $\left(\gamma_{\mathrm{dmax}}\right)$ as shown in Table 1.

Table 1: Properties of clay soil used in the tests.

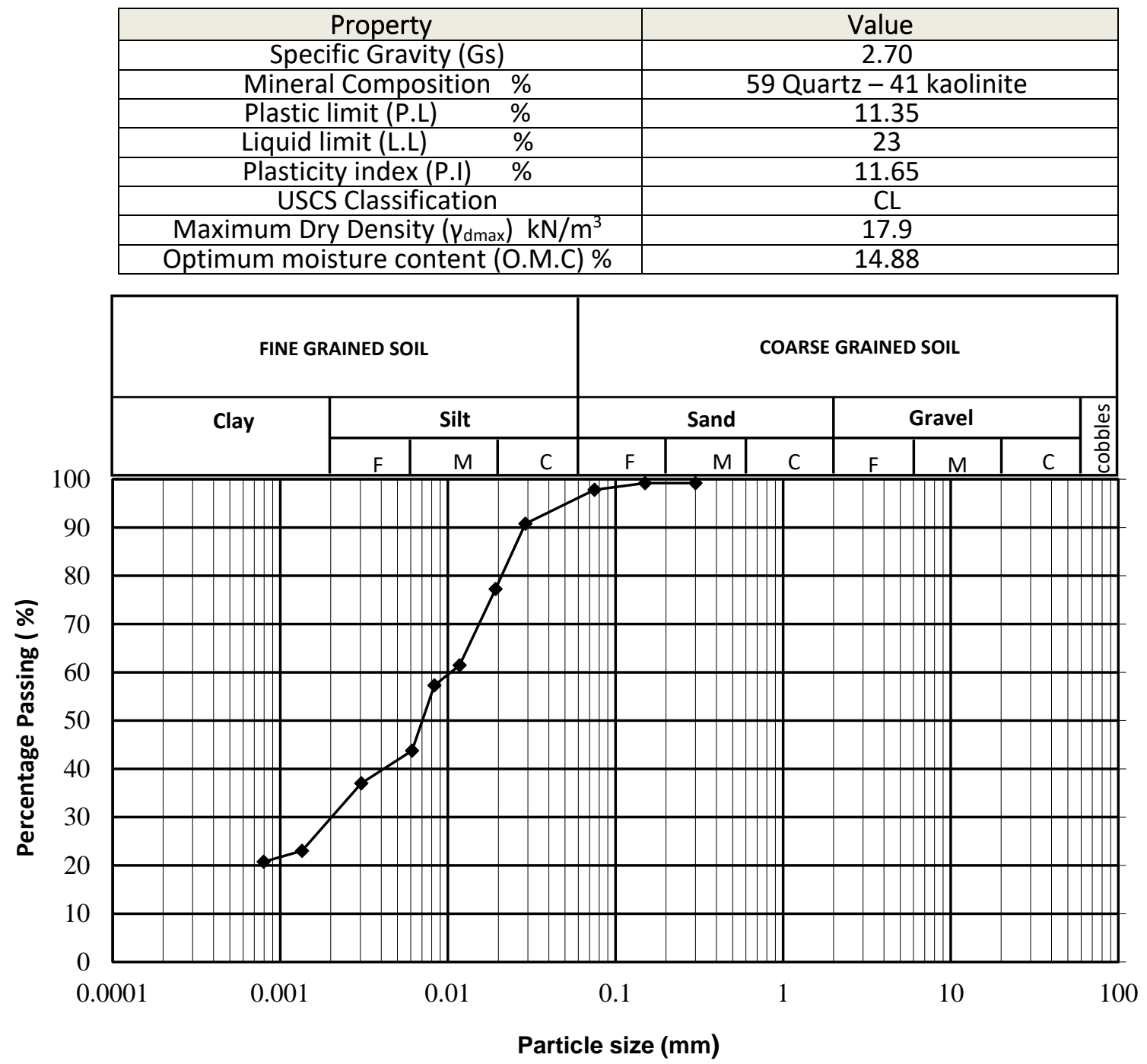

Fig. 1: Grain size distribution curve of clay used in the testing program

Fibers used in this study are Polypropylene fibers (PPF) available in the local Egyptian market and are manufactured by BASF. The commercial name of the fibers is RHEOFIBRE. The specific gravity (Gf) of the fibers is 0.91 . The lengths of the used PPF are $6.0 \mathrm{~mm}, 12 \mathrm{~mm}$, and $18 \mathrm{~mm}$ while the diameter is $0.034 \mathrm{~mm}$. Table 2 summarizes the properties of the used PPF, fig 2 shows photo for RHEOFIBRE used in this study . 


\section{EFFECT OF POLYPROPYLENE FIBERS LENGTH AND CONTENT ON CRACKS \\ DEVELOPMENT IN CLAY LINING}

Table 2: Properties of the used polypropylene fibers.

\begin{tabular}{|cc|c|}
\hline Property & Value \\
\hline Specific Gravity $\left(\mathrm{G}_{\mathrm{s}}\right)$ & 0.91 \\
\hline Length of Fiber $\left(\mathrm{L}_{\mathrm{f}}\right) \quad \mathrm{mm}$ & $(6.0-12.0-18.0)$ \\
\hline The diameter of fiber $\left(\mathrm{d}_{\mathrm{f}}\right)$ & $\mathrm{mm}$ & 0.034 \\
\hline Fiber Tensile Strength $\left(\sigma_{\mathrm{ult}}\right)$ & $\mathrm{MPa}$ & 350 \\
\hline Fiber Elastic Modulus $\quad \mathrm{MPa}$ & 1000 \\
\hline Melting Temperature $\quad{ }^{\circ} \mathrm{C}$ & 165 \\
\hline
\end{tabular}

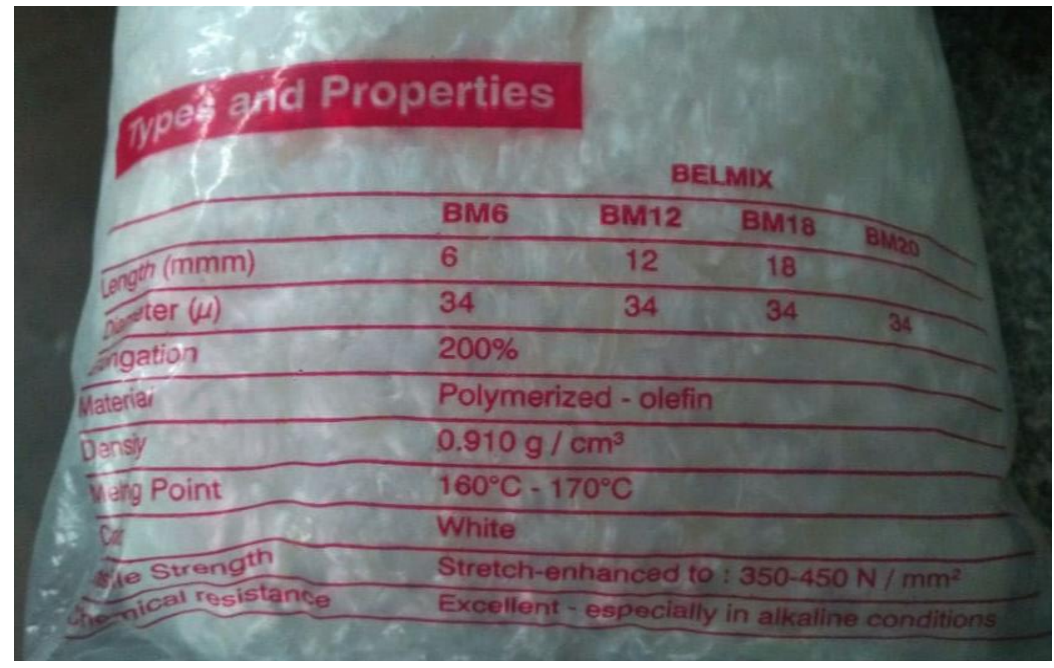

Fig. 2: RHEOFIBRE used in this study

\subsection{Preparation of Test Specimens}

Fibers content $(\mu)$ is characterized in this study as the proportion of the weight of the fibers $\left(\mathrm{W}_{\mathrm{f}}\right)$ to the weight of the solid particles $\left(\mathrm{W}_{\mathrm{s}}\right)$. Polypropylene fibers are expected to supplant a portion of the voids volume within the unreinforced clay to create a reinforced sample with the same relative density.

Unreinforced and reinforced clay specimens are prepared by tamping as recommended by per BS-1377 Part- 7:1990[18]. It is taken into consideration when preparing the sample in layers that the thickness of each layer is multiple times the length of the fiber to allow the fibers to take any orientation. When the layer thickness is close to the length of the fiber, the likelihood of the fibers being horizontally arranged increases.

Segregation of clay was noticed during preparing the mixture. To avoid such segregation, fiber content was taken not to over mix the clay with the fibers. The investigations show that workability problems occur after reaching certain fiber content. In this study, the maximum fiber content used to avoid workability problems and achieve homogeneously mixed specimens is $1.50 \%$. An adequate uniform mixture was achieved by careful mixing and placement of the mixture.

The mixture is then compacted the same way as the unreinforced ones. Few specimens have been repeated to check the repeatability of the outcomes. Thirty-nine of reinforced and unreinforced specimens are tried to guarantee the repeatability of the tests. Samples of reinforced clay with 


\section{EFFECT OF POLYPROPYLENE FIBERS LENGTH AND CONTENT ON CRACKS \\ DEVELOPMENT IN CLAY LINING}

fiber lengths of $6 \mathrm{~mm}, 12 \mathrm{~mm}$ and $18 \mathrm{~mm}$ and fibers contents of $0.0 \%, 0.5 \%, 0.7 \%, 1.0 \%$ and $1.50 \%$ were prepared. The nomenclature given to the specimens is self-explanatory.

\subsection{Testing Program}

The experimental testing program conducted in this study includes a series of Proctor tests to determine maximum dry density $\left(\gamma_{d \max }\right)$ and optimum moisture content (O.M.C) of fiberreinforced clay at different fiber contents $(0.0 \%, 0.5 \%, 0.7 \%, 1.0 \%$ and $1.50 \%)$, and cracking tests to determine the Crack Intensity Factor (CIF) values of fiber-reinforced clay with different lengths at different fiber contents $(0.0 \%, 0.5 \%, 0.7 \%, 1.0 \%$, and $1.50 \%)$. Table 3 summarizes the experimental testing program conducted in this study.

Table 3: Experimental testing program schedule

\begin{tabular}{|c|c|c|c|}
\hline Performed tests & $6 \mathrm{~mm}$ & $12 \mathrm{~mm}$ & $18 \mathrm{~mm}$ \\
\hline \multirow{5}{*}{ A- Proctor tests } & \multicolumn{3}{|c|}{ Unreinforced specimens (0.0\% PPF) } \\
\hline & \multicolumn{3}{|c|}{ Reinforced specimens (0.5\% PPF) } \\
\hline & \multicolumn{3}{|c|}{ Reinforced specimens (0.7\% PPF) } \\
\hline & \multicolumn{3}{|c|}{ Reinforced specimens with $1 \%$ PPF } \\
\hline & \multicolumn{3}{|c|}{ Reinforced specimens with $1.5 \%$ PPF } \\
\hline \multirow{4}{*}{$\begin{array}{l}\text { B- Cracking tests on } \\
\text { unreinforced and } \\
\text { reinforced } \\
\text { samples }\end{array}$} & \multicolumn{3}{|c|}{ Unreinforced specimens (0.0\% PPF) } \\
\hline & \multicolumn{3}{|c|}{ Reinforced specimens (0.5\% PPF) } \\
\hline & \multicolumn{3}{|c|}{ Reinforced specimens (0.7\% PPF) } \\
\hline & \multicolumn{3}{|c|}{ Reinforced specimens with $1 \%$ PPF } \\
\hline \multirow{5}{*}{$\begin{array}{c}\text { C- Cracking tests on } \\
\text { unreinforced and } \\
\text { reinforced } \\
\text { samples under } \\
\text { four (4) drying and } \\
\text { wetting cycles }\end{array}$} & \multicolumn{3}{|c|}{ Reinforced specimens with $1.5 \%$ PPF } \\
\hline & \multicolumn{3}{|c|}{ Reinforced specimens (0.5\% PPF) } \\
\hline & \multicolumn{3}{|c|}{ Reinforced specimens (0.7\% PPF) } \\
\hline & \multicolumn{3}{|c|}{ Reinforced specimens with $1 \%$ PPF } \\
\hline & \multicolumn{3}{|c|}{ Reinforced specimens with 1.5\% PPF } \\
\hline
\end{tabular}

\subsubsection{Standard Proctor Compaction}

The standard Proctor equipment is used to determine $\gamma_{d \max }$ and OMC for the un-reinforced and reinforced clay specimens. A representative oven-dried sample of approximately $5 \mathrm{~kg}$ is obtained for the test. Kaolinite clay is thoroughly mixed with the fibers of the target fibers content then mixed in a soil mixer with sufficient water to dampen it to approximately four to six percentage points below the expected optimum moisture content. The test procedure follows the ASTM D1557[19] standards. 


\section{EFFECT OF POLYPROPYLENE FIBERS LENGTH AND CONTENT ON CRACKS \\ DEVELOPMENT IN CLAY LINING}

\subsubsection{Cracking Test}

The cracking test is conducted in a special test setup and permitted to dry beneath a filament lamp. The cracking test setup is shown in Figure 2, comprised of an encapsulating wooden box $(75 \times 75 \times 75 \mathrm{~cm})$ thermally insulated by $2 \mathrm{~cm}$ thick foam. Three filament lamp spaced at $25 \mathrm{~cm}$ are utilized as the heat source. Three plastic circular containers of $2 \mathrm{~cm}$ depth and $15 \mathrm{~cm}$ diameter are set at $75 \mathrm{~cm}$ underneath the filament lamp. A sensitive balance is utilized to weigh the samples at regular time interims to determine the moisture content value. An infrared thermometer is utilized to measure the temperature amid the test and guarantee a steady temperature of $40{ }^{\circ} \mathrm{C}$. Specimens are prepared in the circular plate at the liquid limit then left to dry in the closed box. The weights were continuously measured to ensure that specimens are totally dry after 24 hours. At each estimated moisture content, photographs are taken to calculate CIF according to the procedure introduced by Miller et al. (1998). Digital image processing software is used to measure the development of cracks in the drying clay. After clay samples are totally dried for 24 hours, specimens are wetted to reach the initial water content then left to dry for another 24 hours, moisture content and CIF measurements have routinely been recorded. Four drying cycles are conducted over four days, counting the initial drying cycle. Three specimens of each fibers content (reinforced or unreinforced) are used to get one CIF value.

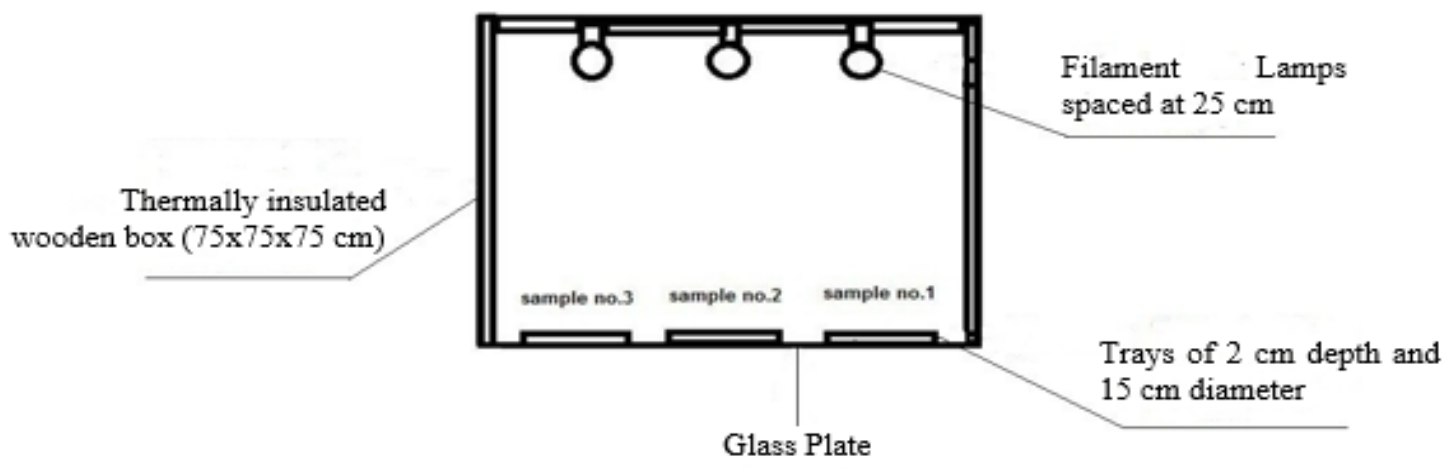

Fig. 3: Schematic drawing of the test setup used for cracking test.

\section{RESULTS AND DISCUSSIONS}

\subsection{Effect of Polypropylene Fibers Inclusions on Compaction Properties}

From the compaction curves shown in the fig (4) to (6) The results of the Proctor compaction tests showed a decrease in $\gamma_{d \max }$ and an increase in the OMC with the increase in fibers content as shown in Figures 7 and 8. The same pattern was observed for fiber-reinforced clays of different lengths. Since the increase in total volume of fibers in the mixture reduces $\gamma_{d m a x}$, as PPF has smaller specific gravity, longer fibers caused more reduction in $\gamma_{\text {dmax }}$ than shorter ones. The compaction test results obtained in this study agree with those presented in the previous studies. 


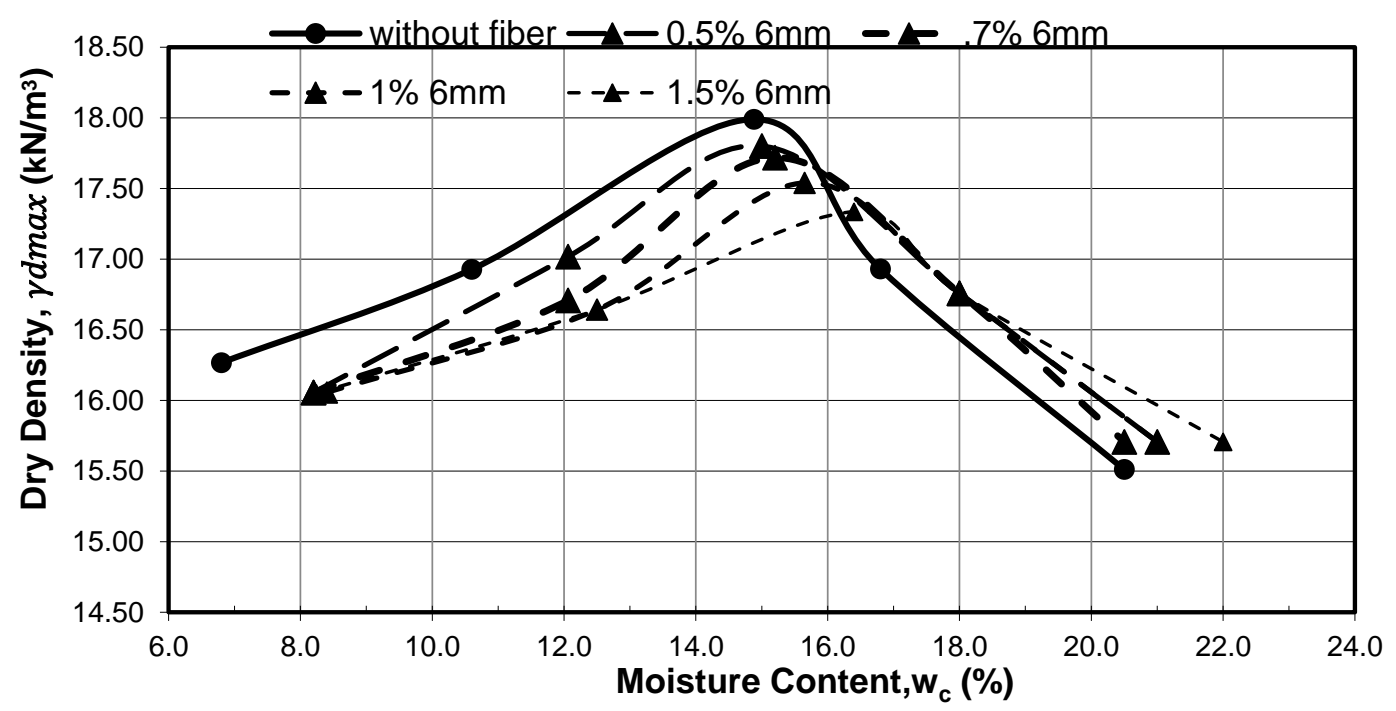

Fig. 4: compaction curves with length $6 \mathrm{~mm}$

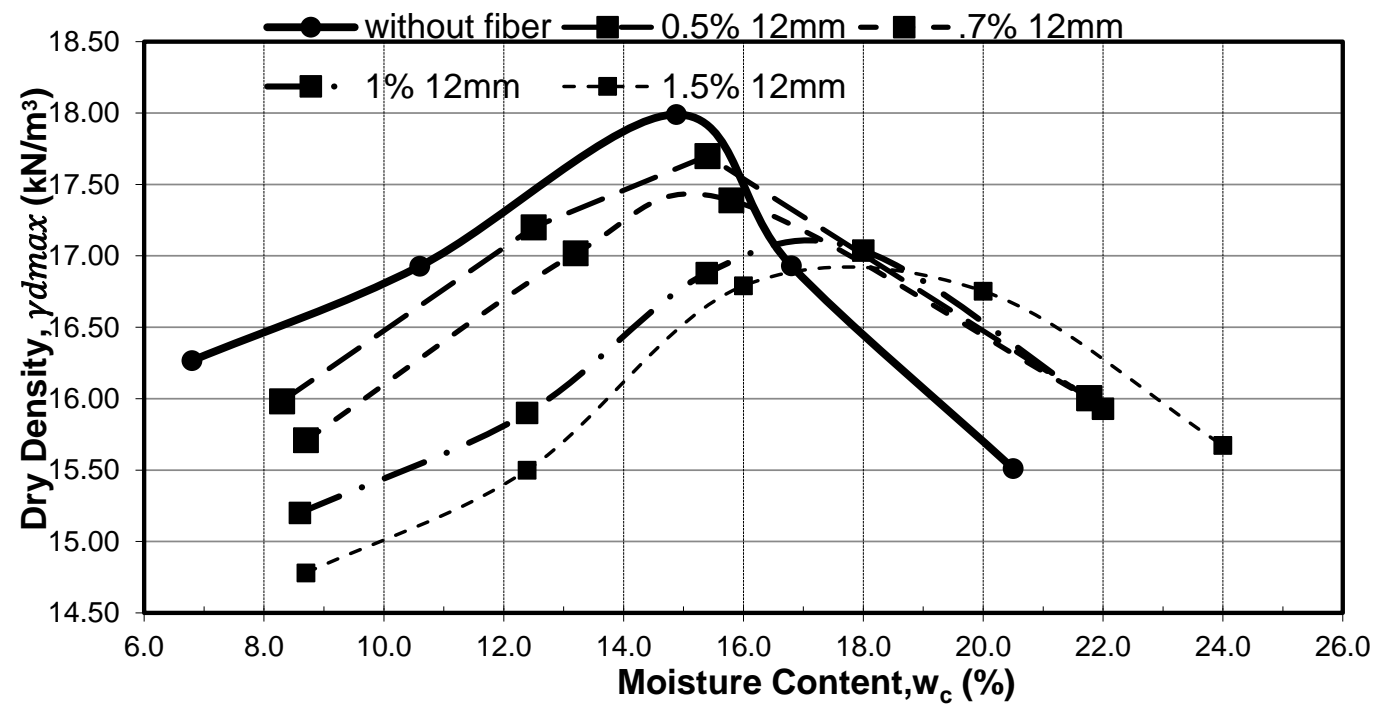

Fig. 5: compaction curves with length $12 \mathrm{~mm}$

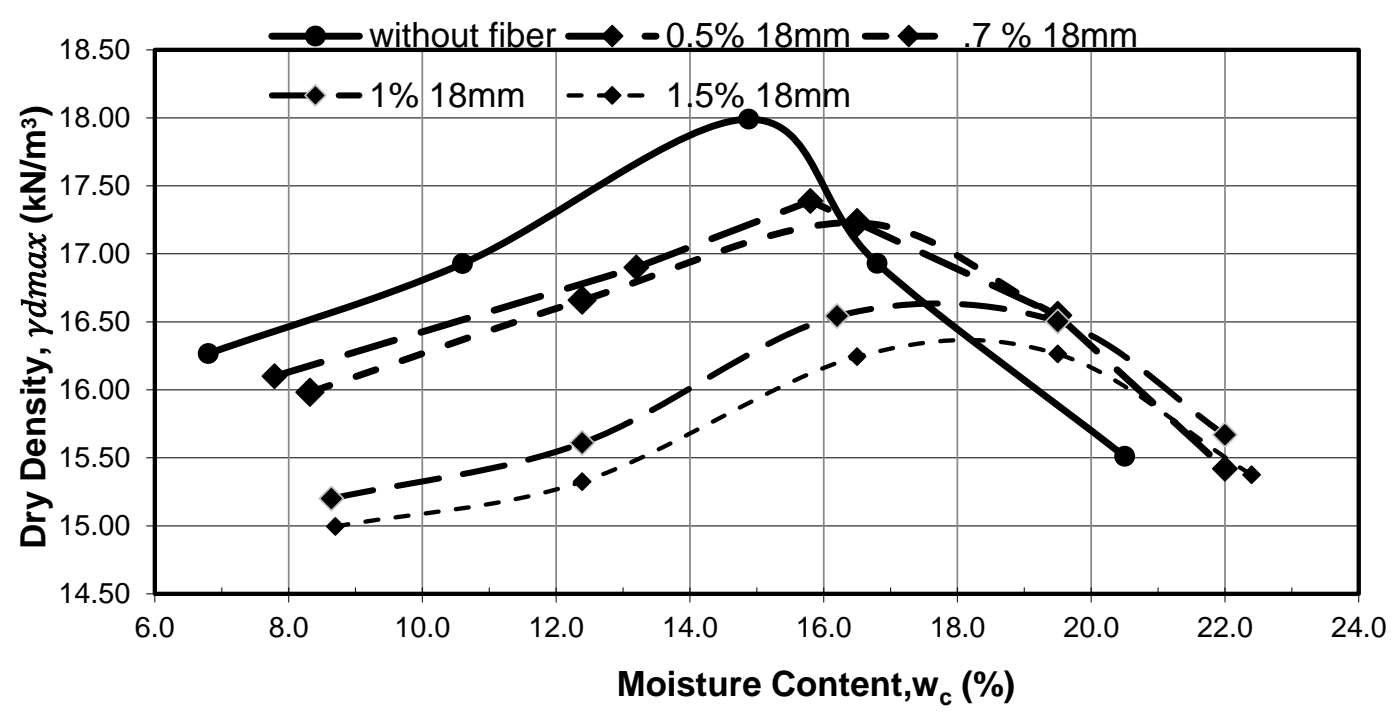

Fig. 6: compaction curves with length $18 \mathrm{~mm}$ 


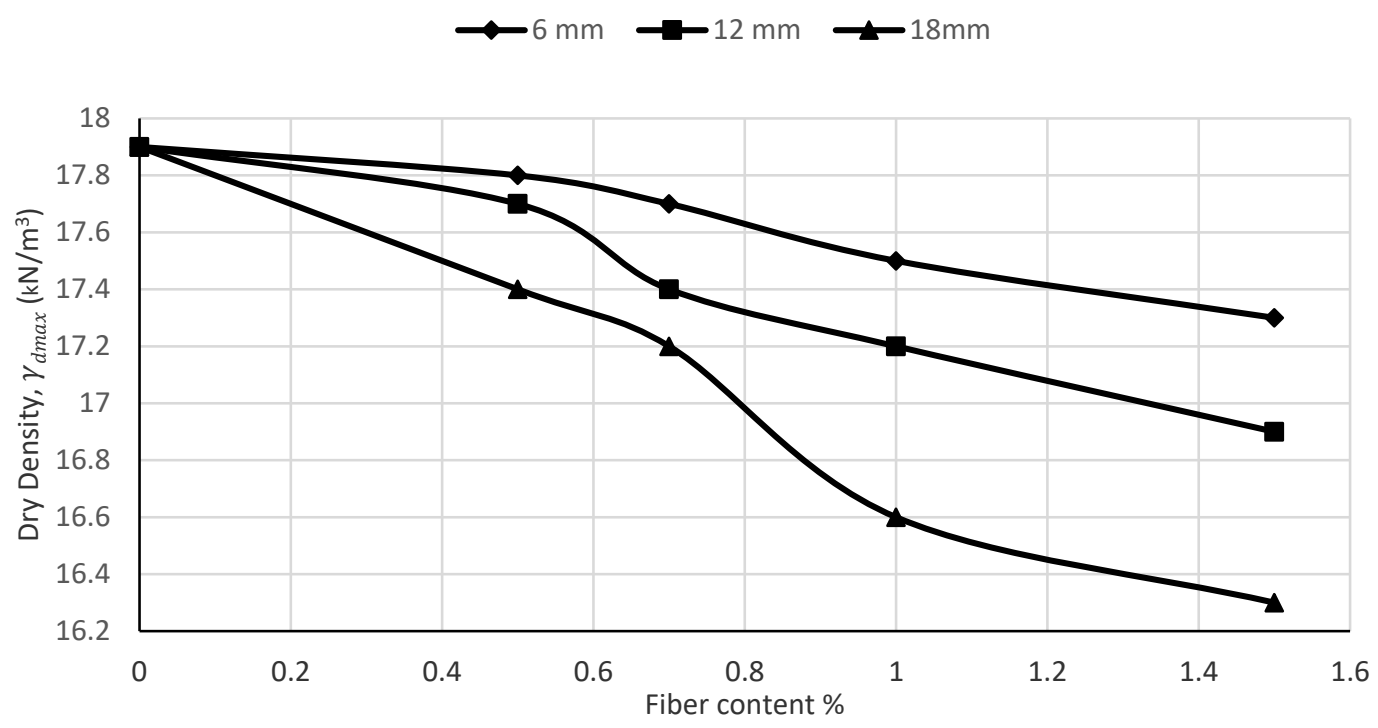

Fig. 7: Variation of $\gamma_{d \max }$ with fibers content and length for tested specimens.

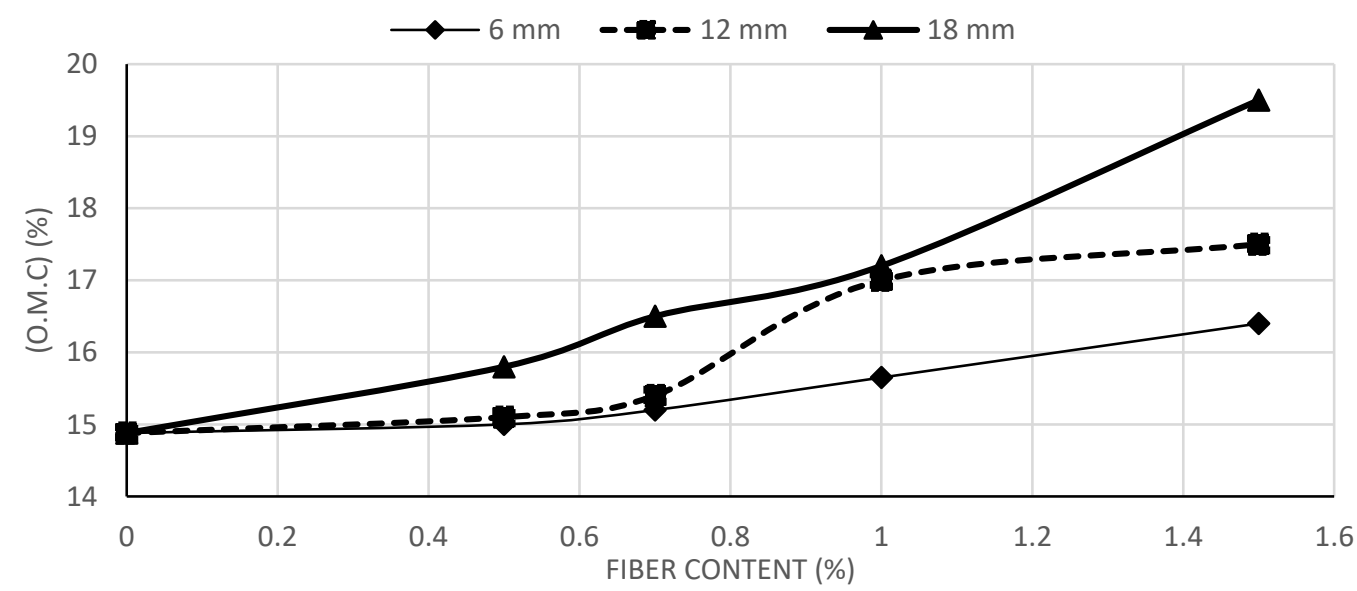

Fig. 8: Change of Optimum moisture content (O.M.C) with fibers content and length for tested specimen

\subsection{Effect of Polypropylene Fibers on Desiccation Cracking}

\subsubsection{Effect of Polypropylene Fibers and Drying Time on Desiccation Cracking}

It is important to capture the time at which no more cracks develop (reaching shrinkage limit) in order to determine the final CIF. Figure 9 depicts the cracking patterns optically captured after 24 hours of drying out for reinforced and unreinforced clay specimens. It is found that after 24 hours of drying, moisture and CIF reaches constant values. The measured CIF values over 36 hours are shown in Figures (9) to (12). 


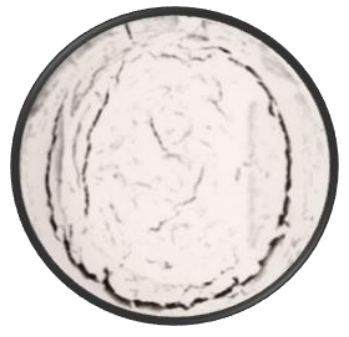

6mm-(a) $0.5 \%$ PPF

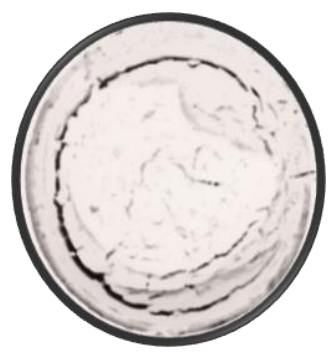

$12 \mathrm{~mm}$-(b) $0.5 \%$ PPF

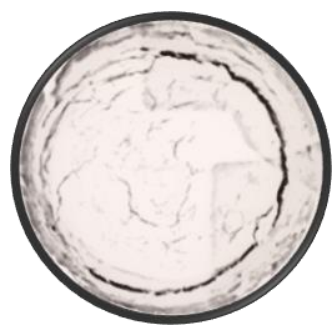

$18 \mathrm{~mm}-(\mathrm{c}) \mathbf{0 . 5 \%}$ PPF

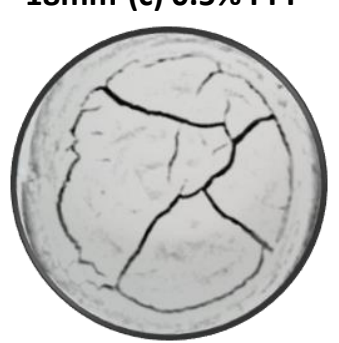

$0 \% \operatorname{PPF}(d)$

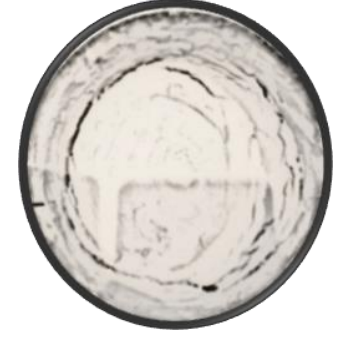

6mm-(a) $0.7 \%$ PPF

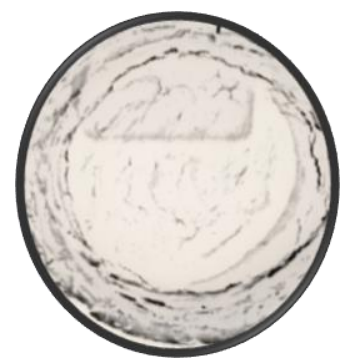

$12 \mathrm{~mm}$-(b) $0.7 \%$ PPF

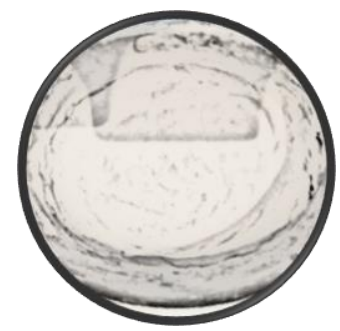

$18 \mathrm{~mm}-(\mathrm{c}) 0.7 \%$ PPF

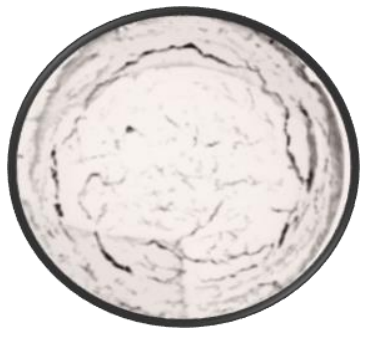

6mm-(a) $1.0 \%$ PPF

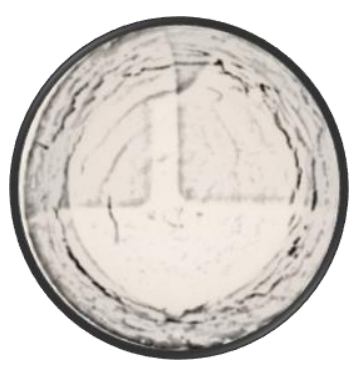

$12 \mathrm{~mm}-(\mathrm{b}) 1.0 \%$ PPF

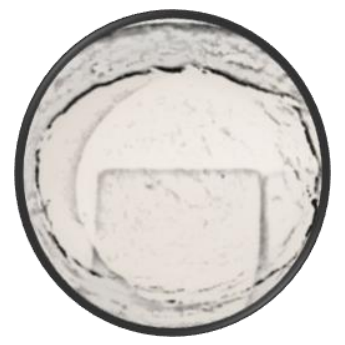

$18 \mathrm{~mm}$-(c) $1.0 \%$ PPF

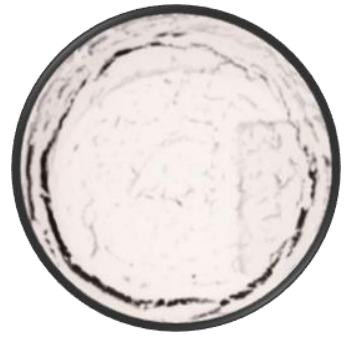

6mm-(a) $1.5 \%$ PPF

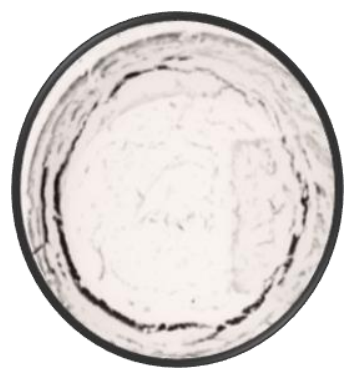

$12 \mathrm{~mm}$-(b) $1.50 \%$ PPF

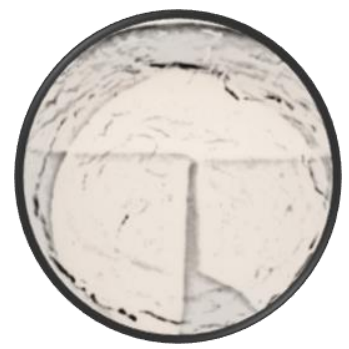

$18 \mathrm{~mm}-$ (c) $1.50 \%$ PPF

Fig. 9: Cracking pattern after 24 hours for (a) reinforced clay $6 \mathrm{~mm}$ PPF, (b) reinforced clay with $12 \mathrm{~mm}$ PPF, and (c) reinforced clay with $18 \mathrm{~mm}$ with different content, and (d) PPF unreinforced clay. 


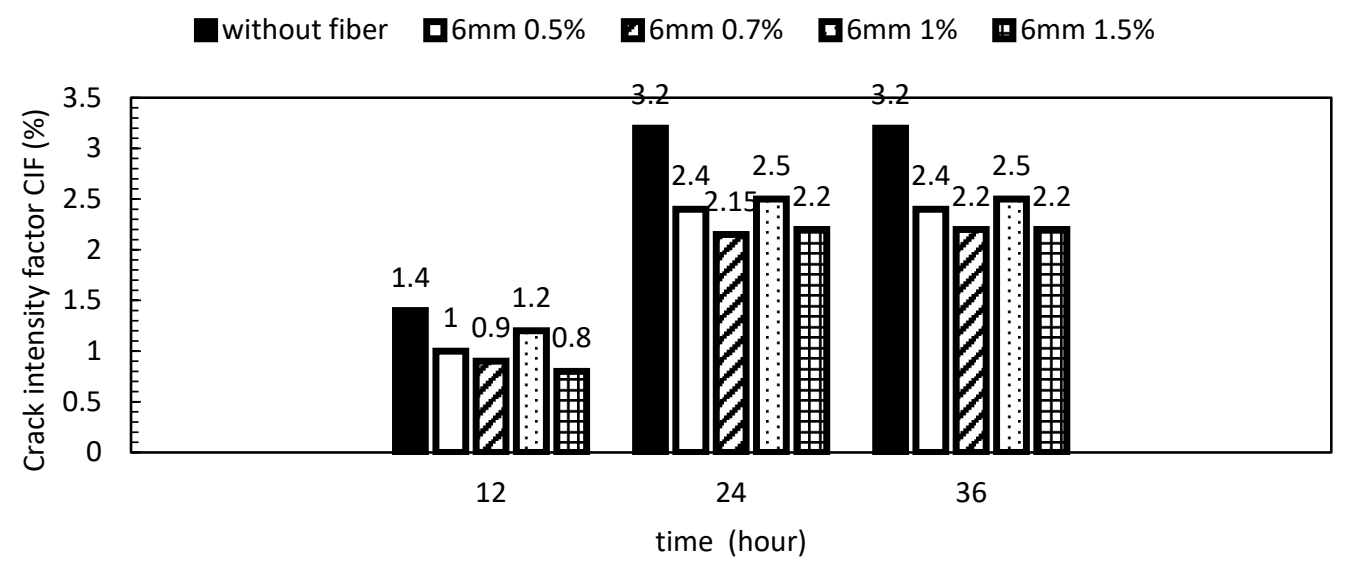

Fig. 10: Variation of crack intensity factor with time for unreinforced and reinforced specimens with $6 \mathrm{~mm}$ PPF.

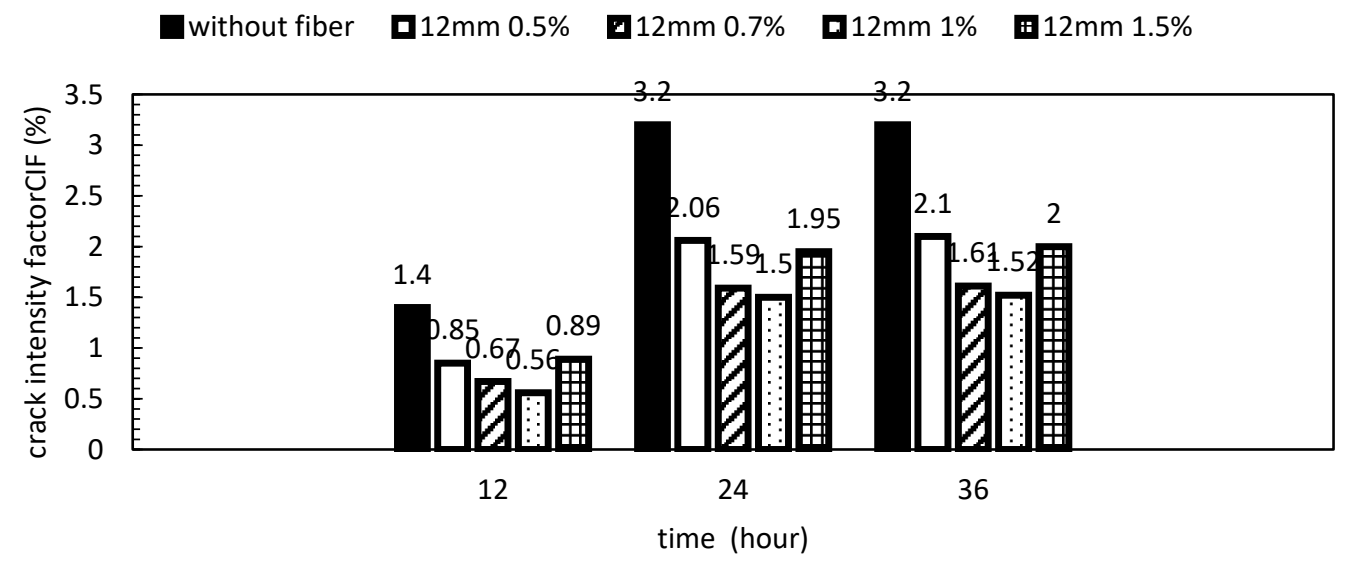

Fig. 11: Variation of crack intensity factor with time for unreinforced and reinforced specimens with $12 \mathrm{~mm}$ PPF.

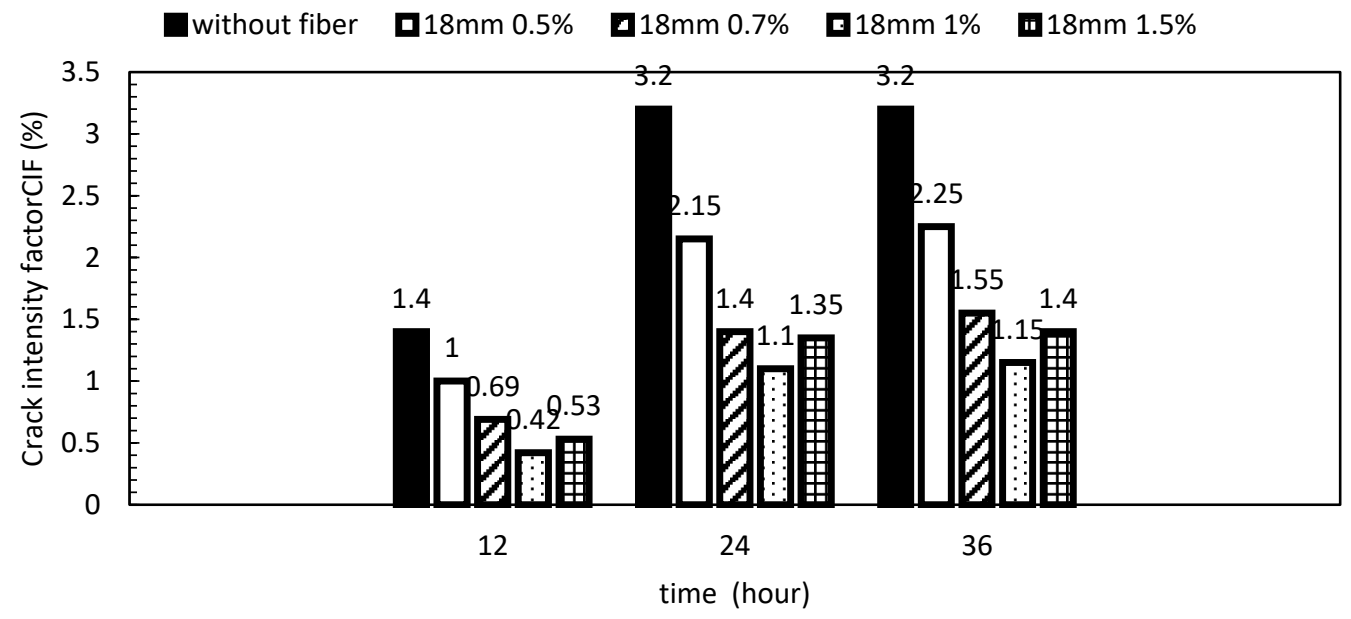

Fig. 12: Variation of crack intensity factor with time for unreinforced and reinforced specimens with $18 \mathrm{~mm}$ PPF. 


\section{EFFECT OF POLYPROPYLENE FIBERS LENGTH AND CONTENT ON CRACKS \\ DEVELOPMENT IN CLAY LINING}

Figure 13 shows a general pattern of decrease in CIF with increase in fibers content for the three fiber lengths. This reduction in CIF (increase in resistance to cracking) reaches a certain fibers content after which, CIF increases. This fiber content at which CIF is minimum will be called hereafter as the optimum fiber content (O.F.C). The optimum fiber content for $6 \mathrm{~mm}$ fibers is found to be $0.7 \%$ while for 12 and $18 \mathrm{~mm}$ fiber its $1 \%$.

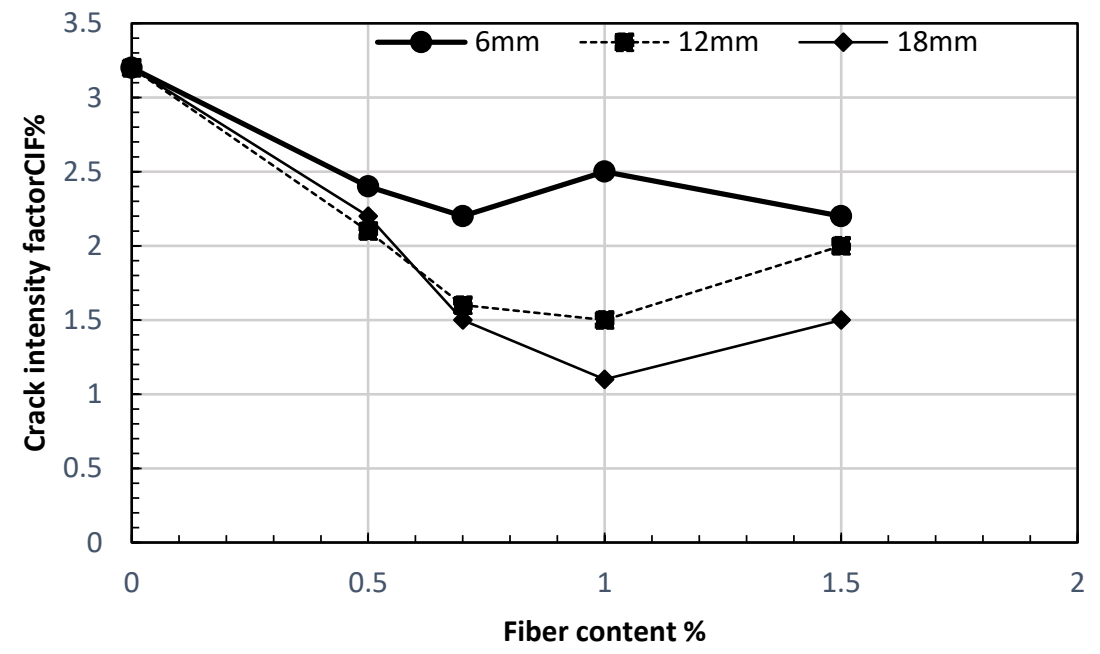

Fig. 13: Variation of crack intensity factor with fiber content for unreinforced and reinforced specimens 6,12 , and $18 \mathrm{~mm}$

Unreinforced specimens develop a coarser network of larger cracks than those of reinforced specimens. Denser cracks network developed in the reinforced specimens with significantly smaller crack widths. The percentage of enhancement in the resistance of cracking (or \% decrease in CIF) for each fiber length and content is summarized in Table 4. The maximum reduction in CIF at (O.F.C) using $6 \mathrm{~mm}$ fiber reached approximately $31.25 \%$ while it reached $53.125 \%$ and $65.625 \%$ for $12 \mathrm{~mm}$ and $18 \mathrm{~mm}$ fibers, respectively.

Table 4: Percentage of reduction in CIF for each fiber length and content

\begin{tabular}{|c|c|c|c|}
\hline $\begin{array}{c}\text { Fibers content } \\
\text { (\%) }\end{array}$ & $\mathbf{6 m m}$ & $\mathbf{1 2 m m}$ & $\mathbf{1 8 m m}$ \\
\hline $\mathbf{0 . 5}$ & $25 \%$ & $34.375 \%$ & $31.25 \%$ \\
\hline $\mathbf{0 . 7}$ & $31.25 \%$ & $50 \%$ & $53.125 \%$ \\
\hline $\mathbf{1}$ & $21.875 \%$ & $53.125 \%$ & $65.625 \%$ \\
\hline $\mathbf{1 . 5}$ & $31.25 \%$ & $37.5 \%$ & $53.125 \%$ \\
\hline
\end{tabular}

. Larger CIF after (O.F.C) can be attributed to the presence of a larger number of soil-fiber interfaces facilitating the onset for crack initiations. These results are in agreement with the UCS results presented earlier in this paper. Qiang et al. (2014) and Chaduvula et al. (2017) also reported an 


\section{EFFECT OF POLYPROPYLENE FIBERS LENGTH AND CONTENT ON CRACKS \\ DEVELOPMENT IN CLAY LINING}

increase in the resistance to cracking up to certain fibers contents after which, such resistance decreases.

\subsubsection{Effect of Wetting-Drying Cycles on Cracks Development}

Unreinforced and reinforced clays prepared at liquid limit are subjected to four consequent wettingdrying cycles. Subsequent wetting is applied to the specimens then allowed to dry until no change in moisture or CIF is observed. All wetting and drying processes take place in the setup shown earlier in fig (3). Images are regularly captured for CIF measurements. Figures (14) to (16) show the continuous evolution of CIF over time showing how cracks heal when specimens are wetted at the beginning of each cycle. From Figures 10 to12, it is clear that all specimens developed fewer cracks during the first cycle than during the subsequent cycles..

There is a general consensus in the published studies on the negative effect of multiple wetting and drying cycles on effectiveness of the fiber inclusion to reduce resisting desiccation cracking (Ziegler et al., (1998) [15]; Yesiller et al., (2000) ; Qiang et al., (2014) ; Estabragh et al., (2014) ; and Galaa et al., (2018). Yesiller et al. (2000) provided a detailed explanation for reduced resistance to cracking upon wetting and drying where such deterioration is attributed to softening is soil strength upon each wetting cycle. Subsequent drying to each of the wetting cycles induces suction; which exceeds the resistance of the weakened soils causing cracking at locations of decreased soil strength. The soil fabric experiences irreversible changes during the wetting of compacted soil after the first cycle. Wetting may induce healing of some or all of the developed cracks. However, crack locations remain weaker and reopens with each drying cycle. In addition, healed crack locations represent a favorable zone for the inception of further cracks. Therefore, the energy (suction) required to develop new cracks is less than that required in the first cycle.

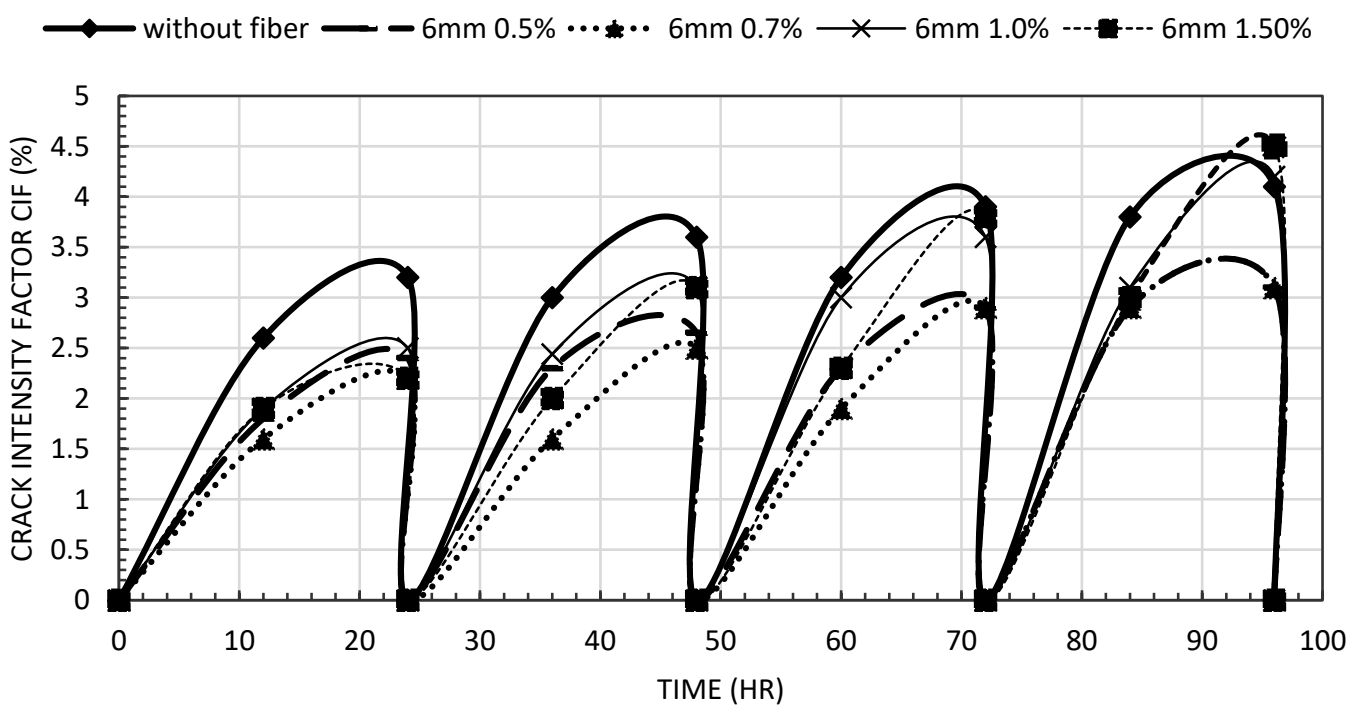

Fig. 14: Development of crack intensity factor with time over the four drying cycles for unreinforced and reinforced clay with $6 \mathrm{~mm}$ PPF. 


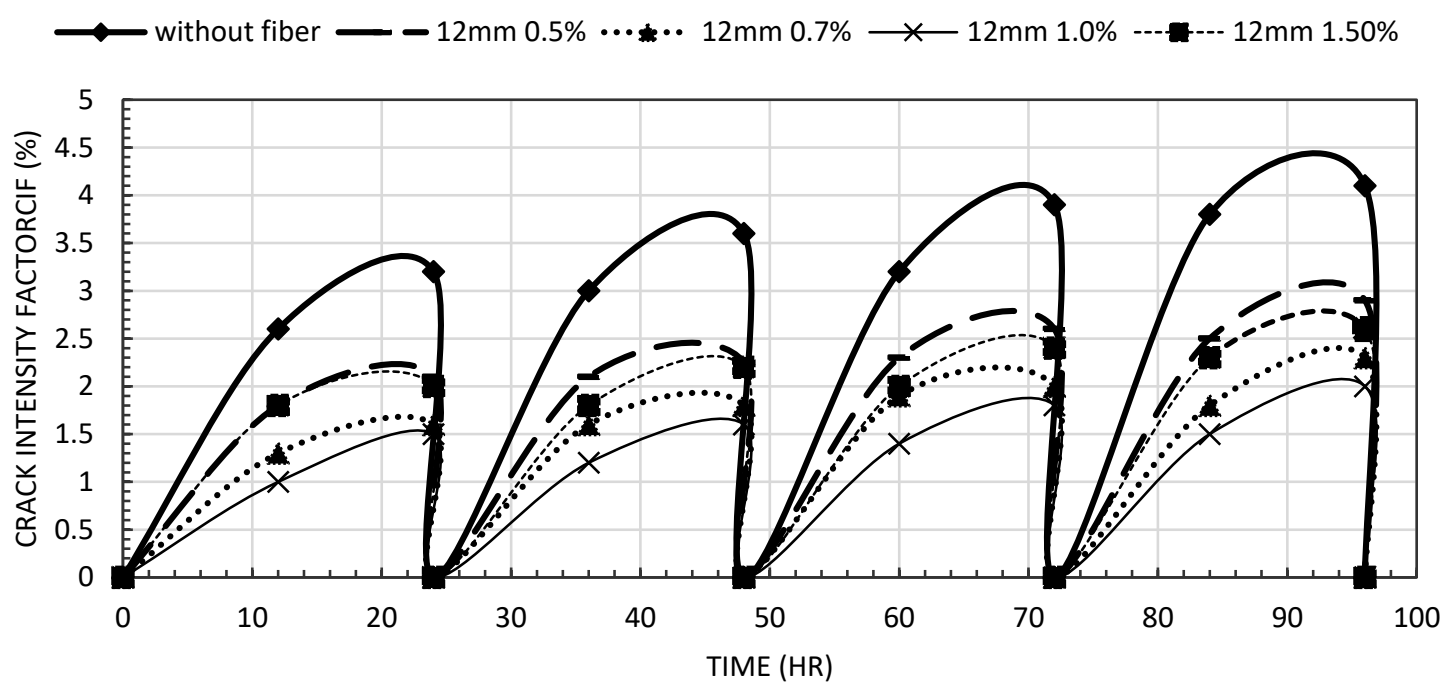

Fig. 15: Development of crack intensity factor with time over the four drying cycles for unreinforced and reinforced clay with $12 \mathrm{~mm}$ PPF.

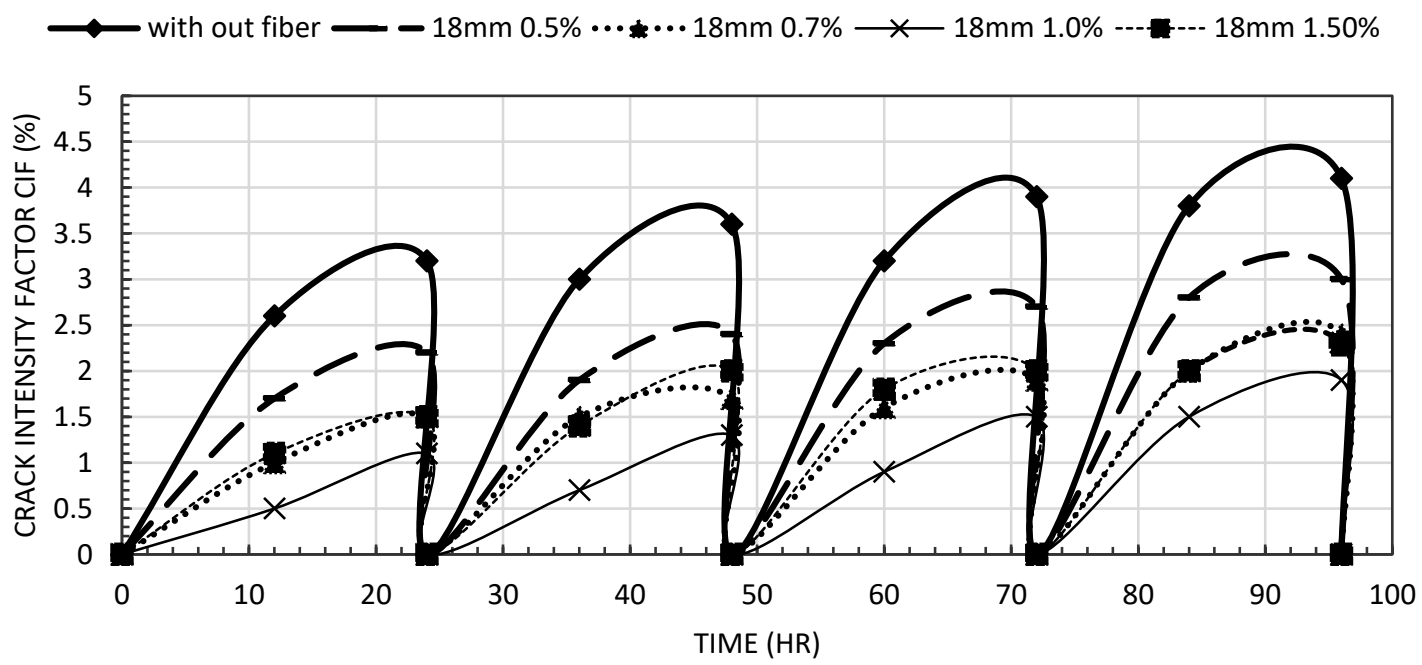

Fig. 16: Development of crack intensity factor with time over the four drying cycles for unreinforced and reinforced clay with $18 \mathrm{~mm}$ PPF

Figures 17 to 19 show CIF development at the end of each drying cycle and the percentage of reduction in CIF for each fiber length and content at the end of each drying cycle are listed in table 5. From these results it is clear that, longer fibers $(12$ and $18 \mathrm{~mm})$ showed better resistance to cracking after four cycles reaching a reduction in CIF of $51.21 \%$ and $53.65 \%$, respectively. The short fiber (6 $\mathrm{mm}$ ) showed that, excessive inclusion of short PPF deteriorates the resistance to cracking for clays subjected to multiple wetting-drying cycles. Such results are in agreement with Galaa et al. (2018). Ziegler et al. (1998) as the effectiveness of high fiber contents in cracks control is significantly reduced after multiple wetting-drying cycles, particularly for specimens with lower plasticity indices. 


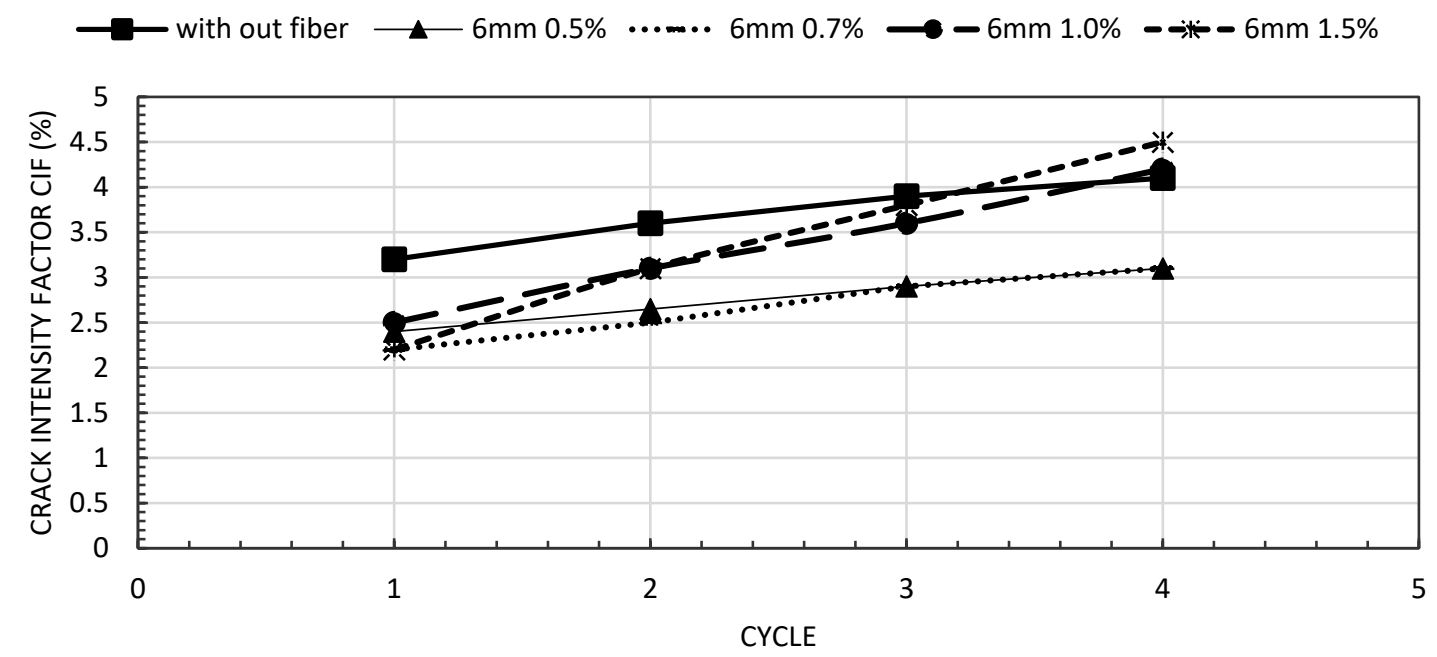

Fig. 17: Variation of crack intensity factor with cycle for unreinforced and reinforced specimens with 6 mm PPF.

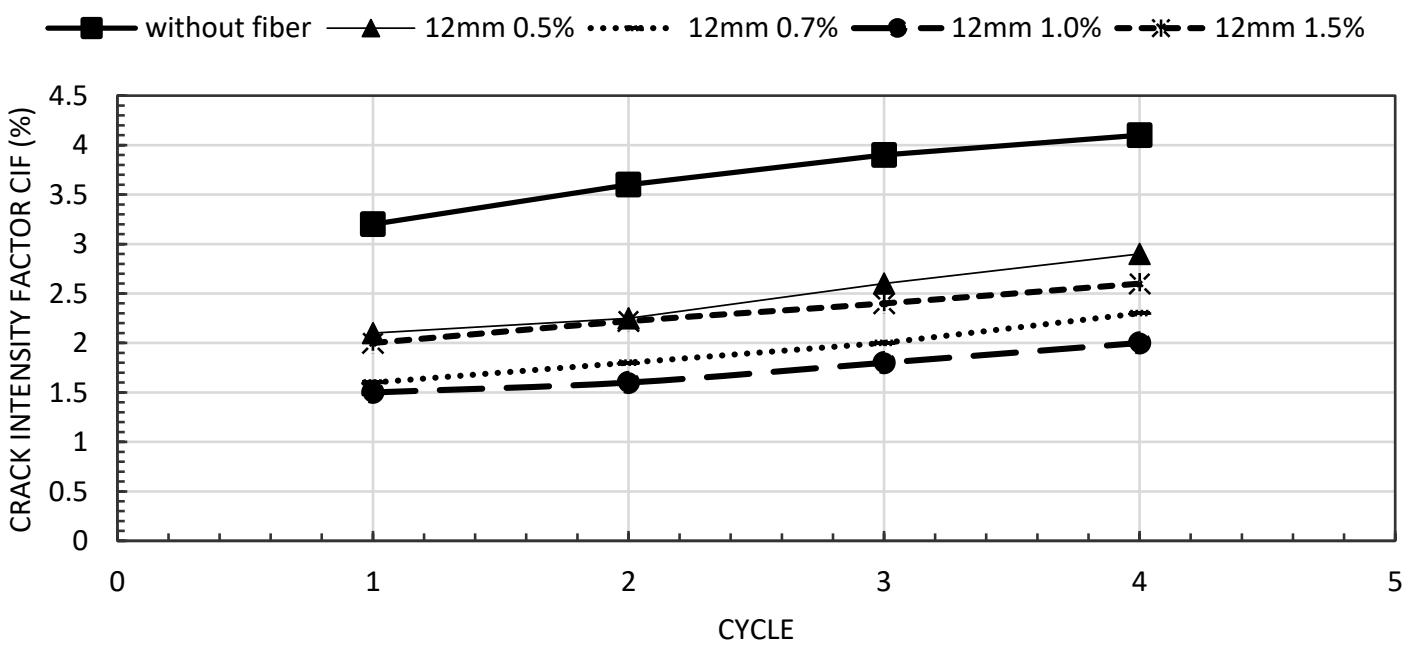

Fig. 18: Variation of crack intensity factor with cycle for unreinforced and reinforced specimens with 12 mm PPF. 


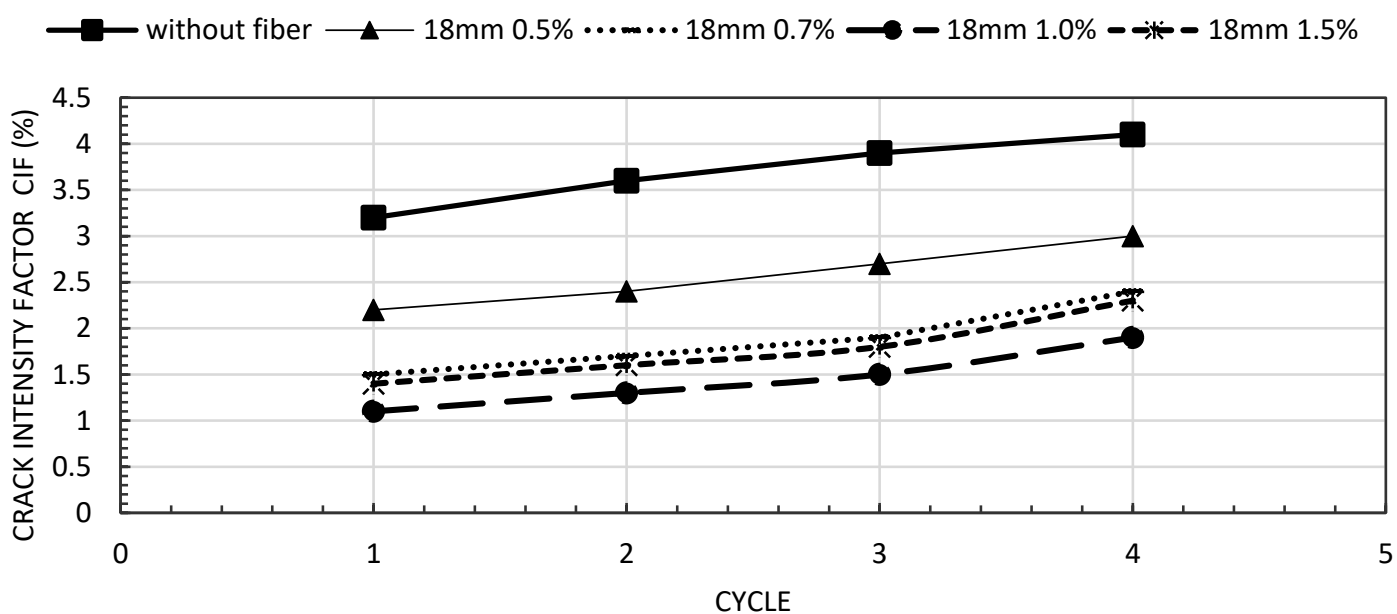

Fig. 19: Variation of crack intensity factor with cycle for unreinforced and reinforced specimens with 18 $\mathrm{mm}$ PPF.

Table 5: Percentage of reduction in CIF for each fiber length and content at the end of each drying cycle

\begin{tabular}{|c|c|c|c|c|c|c|c|c|c|c|c|c|}
\hline $\begin{array}{c}\text { Fibers } \\
\text { content } \\
(\%)\end{array}$ & $\begin{array}{c}\text { Cycle 1 } \\
\%\end{array}$ & $\begin{array}{c}\text { Cycle 2 } \\
\%\end{array}$ & $\begin{array}{c}\text { Cycle 3 } \\
\%\end{array}$ & $\begin{array}{c}\text { Cycle 4 } \\
\%\end{array}$ & $\begin{array}{c}\text { Cycle 1 } \\
\%\end{array}$ & $\begin{array}{c}\text { cycle 2 } \\
\%\end{array}$ & $\begin{array}{c}\text { Cycle 3 } \\
\%\end{array}$ & $\begin{array}{c}\text { Cycle 4 } \\
\%\end{array}$ & $\begin{array}{c}\text { Cycle 1 } \\
\%\end{array}$ & $\begin{array}{c}\text { Cycle 2 } \\
\%\end{array}$ & $\begin{array}{c}\text { cycle 3 } \\
\%\end{array}$ & $\begin{array}{c}\text { Cycle 4 } \\
\%\end{array}$ \\
\hline $\mathbf{0 . 5}$ & 25 & 26.38 & 25.64 & 24.39 & 34.37 & 37.5 & 33.33 & 29.26 & 30.25 & 33.33 & 30.76 & 26.82 \\
\hline $\mathbf{0 . 7}$ & 31.25 & 30.55 & 25.64 & 24.39 & 50 & 50 & 48.71 & 43.90 & 53.12 & 52.77 & 51.28 & 41.46 \\
\hline $\mathbf{1}$ & 21.87 & 13.88 & 7.69 & -2.4 & 53.12 & 55.55 & 53.12 & 51.21 & 65.63 & 63.88 & 61.53 & 53.65 \\
\hline $\mathbf{1 . 5}$ & 31.25 & 13.88 & 2.56 & -9.7 & 37.5 & 38.33 & 38.46 & 36.58 & 56.25 & 55.55 & 53.84 & 43.90 \\
\hline
\end{tabular}

\section{CONCLUSIONS}

From the experimental study carried out in this paper, the following conclusions are obtained:-

1- Increasing the fiber content reduces maximum dry density and increases optimum moisture content. The increasing in polypropylene fibers volume within the mixture of soil and fiber is the main reason for reduction in maximum dry density.

2- Reinforcing clay with polypropylene fibers increases the resistance to cracking. This resistance increases by increasing the fibers content until an optimum fiber content, after which the resistance to cracking decreases.

3- The optimum fiber content increases with the increase in fibers length. Specimens with 6 $\mathrm{mm}$ fibers has optimum fiber content of $0.7 \%$, while those with 12 and $18 \mathrm{~mm}$ fibers have optimum fiber content of $1 \%$. The maximum reduction in crack intensity factor at optimum 


\section{EFFECT OF POLYPROPYLENE FIBERS LENGTH AND CONTENT ON CRACKS \\ DEVELOPMENT IN CLAY LINING}

fiber content using $6 \mathrm{~mm}$ fiber reaches approximately $31.25 \%$ while it reaches $53.125 \%$ and $65.625 \%$ for $12 \mathrm{~mm}$ and $18 \mathrm{~mm}$ fibers, respectively.

4- The longer fibers (12 and $18 \mathrm{~mm}$ ) shows better resistance to cracking after multiple wetting drying cycles. The reduction in crack intensity factor reaches $51.21 \%$ for length $12 \mathrm{~mm}$ and $53.65 \%$ for length $18 \mathrm{~mm}$, relative to the unreinforced clay sample at the same cycle.

5- Fiber with length $(6 \mathrm{~mm})$ shows that excessive inclusion of short polypropylene fibers deteriorates the resistance to cracking for clays subjected to multiple wetting-drying cycles for clay reinforced with $6 \mathrm{~mm}$ fibers at $1 \%$ and $1.5 \%$ fibers content.

\section{REFERENCES:}

1. BSI British Standards Institution (1990), Soils for Civil Engineering Purposes : Part 7. Shear Strength Tests, British Standard BS 1377:Part 7.

2. Chegenizadeh, A., \& Nikraz, H. (2012). Effect of clay layer thickness on desiccation and cracking. Proceedings of the 5th Asia-Pacific Conference on Unsaturated Soils (AP-UNSAT 2011) (pp. 659-662). Kasetsart University, Thailand..

3. Chegenizadeh, A., \& Nikraz, H. (2011). Study on strength of fiber reinforced clayey sand. Proceedings of the International Conference on Science and Engineering (ICSE 2011) (pp. 356-359). Research Publishing Services..

4. Chaduvula, U., Viswanadham, B. V. S., \& Kodikara, J. (2017). A study on desiccation cracking behavior of polyester fiber-reinforced expansive clay. Applied Clay Science, 142, $163-172$.

5. Estabragh, A. R., Parsaei, B., \& Javadi, A. A. (2015). Laboratory investigation of the effect of cyclic wetting and drying on the behaviour of an expansive soil. Soils and foundations, 55(2), 304-314.

6. Galaa, A. M., Yousef, M. S., \& Morsy, M. M. (2018). Effect of polypropylene fibers inclusion on the mechanical behavior of clayey soil. proceedings of fifteenth international conference on structural and geotechnical engineering, Cairo, Egypt, December 2018.

7. Maher, M. H., \& Ho, Y. C. (1994). Mechanical properties of kaolinite/fiber soil composite. Journal of Geotechnical Engineering, 120(8), 1381-1393.

8. Malekzadeh, M., Bilsel, H., 2012. "Effect of Polypropylene Fiber on Mechanical Behaviour of Expansive Soils", EJGE, 17, 55-63.

9. Maheshwari, K., Solanki, C. H., \& Desai, A. K. (2013). Effect of polyester fibers on strength properties of clayey soil of high plasticity. International Journal of Scientific \& Engineering Research, 4(6), 486-491.

10. Noorzad, R., \& Mirmoradi, S. H. (2010). Laboratory evaluation of the behavior of a geotextile reinforced clay. Geotextiles and Geomembranes, 28(4), 386-392..

11.Ple, O., \& Lê, T. N. H. (2012). Effect of polypropylene fiber-reinforcement on the mechanical behavior of silty clay. Geotextiles and Geomembranes, 32, 111-116.

12. Qiang, X., Hai-jun, L., Zhen-ze, L., \& Lei, L. (2014). Cracking, water permeability and deformation of compacted clay liners improved by straw fiber. Engineering Geology, 178, 82-90. 


\section{EFFECT OF POLYPROPYLENE FIBERS LENGTH AND CONTENT ON CRACKS \\ DEVELOPMENT IN CLAY LINING}

13. Rifai, S. M., \& Miller, C. J. (2009). Theoretical assessment of increased tensile strength of fibrous soil undergoing desiccation. Journal of geotechnical and geoenvironmental engineering, 135(12), 1857-1862.

14. Sabat, A. K. (2012). Effect of polypropylene fiber on engineering properties of rice husk ash-lime stabilized expansive soil. Electronic Journal of Geotechnical Engineering, 17, 651660 .

15. Salim, N., Al-Soudany, K., \& Jajjawi, N. (2018). Geotechnical properties of reinforced clayey soil using nylons carry's bags by products. In MATEC Web of Conferences (Vol. 162, p. 01020). EDP Sciences.

16. Standard, A. S. T. M. (2009). D1557. Standard Test Methods for Laboratory Compaction Characteristics of Soil Using Modified Effort, ASTM International, West Con-shohocken, PA.

17. Tang, C., Shi, B., Gao, W., Chen, F., \& Cai, Y. (2007). Strength and mechanical behavior of short polypropylene fiber reinforced and cement stabilized clayey soil. Geotextiles and Geomembranes, 25(3), 194-202.

18. Yesiller, N., Miller, C., Inci, G., Yaldo, K., 1999. "Desiccation and cracking behavior of three compacted landfill liner soils", Engineering Geology, 57(1-2), 105-121.

19.Ziegler, S., Leshchinsky, D., Ling, H. I., \& Perry, E. B. (1998). Effect of short polymeric fibers on crack development in clays. Soils and Foundations, 38(1), 247-253. 